SHOCK OF BIRTH

\title{
EVALUATION OF NEUROLOGIC STATUS OF TERM NEWBORN IN THE FIRST 48 HOURS OF LIFE
}

\author{
RUDIMAR DOS SANTOS RIESGO*, ALEXANDRE TELLECHEA ROTTA**, \\ NEWRA TELLECHEA ROTTA***
}

\begin{abstract}
The shock of birth is a transient depression of muscle tone and deep tendon reflexes seen in newborn babies shortly after birth. We evaluated the shock of birth in a sample of 313 consecutive term newborns at 4,24 and 48 hours of life. We correlated neurologic findings on examination with maternal, obstetric and perinatal data. Special attention was given to the relationship between the mode of delivery and shock of birth. Of the maternal data, factors associated with the shock of birth were obstetric gestational age, previous gestations, abortions or previous vaginal deliveries. Presence of stained amniotic fluid at birth was associated with the shock of birth. There was also a correlation between shock of birth and newborn sex, birth weight, thoracic circumference and the Battaglia and Lubchenco classification. The shock of birth lasted less than 24 hours in $70 \%$ of the newborns and less than 48 hours in $84.3 \%$. We conclude that the mode of delivery, vaginal or cesarean section, did not influence the shock of birth. We also established the duration and factors associated with this phenomenon.
\end{abstract}

KEY WORDS: shock of birth, neurologic examination, term newborn.

Choque do nascimento: avaliaçāo do vigor neurológico do recém-nascido a termo nas primeiras 48 horas de vida

RESUMO - O choque do nascimento é uma depressão temporária do tono muscular e reflexos em recémnascidos. Nós o avaliamos em uma amostra de 313 recém-nascidos a termo, de partos consecutivos, examinados com 4, 24 e 48 horas de vida. Correlacionamos os achados do exame neurológico com dados matemos, do parto e do recém-nascido, com ênfase na relação entre o tjpo de parto e o choque do nascimento. Dentre os dados maternos, estiveram associados com o choque do nascimento: idade gestacional obstétrica, gestações, abortamentos e partos vaginais prévios. $O$ único dado do parto que esteve associado foi a presença de líquido amniótico não claro. Sexo, peso ao nascimento, perímetro torácico e classificação de Battaglia \& Lubchenco foram os dados do recém-nascido que estiveram associados com o evento. $O$ choque do nascimento durou menos de 24 horas em 70\% dos recém-nascidos e até 48 horas em $84,3 \%$ deles. Concluímos que o tipo de parto, se vaginal ou cesáreo, nāo exerce influência no choque do nascimento. Também estabelecemos sua duração e os fatores que estão associados com este fenômeno.

PALAVRAS-CHAVE: choque do nascimento, exame neurológico, recém-nascido a termo.

The change from liquid to gas environment that occurs immediately after birth is responsible for profound physiologic changes in virtually every organ system ${ }^{8,27}$. The nervous system undergoes

Division of Neurology, Hospital de Clinicas de Porto Alegre, Universidade Federal do Rio Grande do Sul (UFRS), Porto Alegre, Brazil: * M.D., Child Neurologist, Master in Pediatrics; ** M.D., Pediatrician, The Children's Hospital of Buffalo; *** M.D., Ph.D., Child Neurologist, Associate Professor of Neurology at UFRGS. Aceite: 26-março-1996.

Dr. Rudimar dos Santos Riesgo - Rua São Vicente 513/704 - 90630-180 Porto Alegre RS - Brasil. 
a phase of transient depression shortly after birth, with noticeable changes in reflexes and muscle tone. This phenomenon is called "shock of birth". The term shock of birth was proposed by Escardó and Coriat 36 years ago $^{15}$ and since gained acceptance by several authors ${ }^{3,10-13,19,25,30,31}$. However, this phase of the neurobehavioral adaptation of term newborns has been subject of very few investigations, most of them with study methodology or design problems. The landmark paper on shock of birth ${ }^{15}$ only studied babies born by vaginal delivery. Very little is known about the physiologic effects of cesarean section deliveries on the neurologic performance of the newborn ${ }^{17.23}$.

We undertook an observational study to evaluate a sample of 313 consecutive term newborns delivered at Hospital de Clínicas de Porto Alegre. Our goals were to evaluate the shock of birth by monitoring the neurologic vigor of newborns in the first 48 hours of life, utilizing the Neurologic and Adaptative Capacity Score (NACS) 4 . We also studied the correlation between the mode of delivery (cesarean or vaginal) on the shock of birth as well as the duration of this phenomenon.

\section{PATIENTS AND METHODS}

We conducted a prognostic prospective cohort study. Data were evaluated considering maternal factors, obstetric factors and newborns factors. The clinical outcome was the shock of birth, established by the NACS ${ }^{4}$. Sample size was calculated after a pilot study involving 30 newborns (not included in this sample). The calculated sample size was 303 newborns in order to confer a 90\% statistical power with a $p$ value of $5 \%$. We estimated that 16 weeks would have been necessary to achieve the minimum sample size, using randomly selected weekly 12 hours shifts. Data collection was terminated on the 15 th week due to a satisfactory sample size.

We enrolled newborns bom by vaginal delivery or elective cesarean section with obstetric or pediatric gestational ages equal or greater to 37 weeks. The pediatric gestational age was used in cases where there was a difference of more than 2 weeks between the obstetric and pediatric gestational ages.

Babies born by vaginal route with pelvic or rotated cephalic presentations were excluded from the study. We also excluded newborns that had evidence of fetal distress indicated by obstetric evaluation, as well as those that required observation or treatment in the neonatal intensive care unit.

Data were collected in standard spreadsheets and stored using DBASE III Plus sofware. Statistical analysis was performed with EPI-INFO and SPSS. The chi-square test, Fischer exact test, Mann-Whitney test and multiple logistic regression analysis were used when appropriate. A $p$ value equal or smaller than 0.05 was considered statistically significant.

We studied the assaciation between the shock of birth and maternal data (age, marital status, race, residence, obstetric gestational age, parity and prenatal care), obstetric data (total duration of labor, duration of second stage of labor, membrane rupture, mode of delivery, placental weight, amniotic fluid characteristics, presence of episiotomy, use of induction agents or forceps and type of anesthesia or analgesia) and newborn data (sex, race, presentation, birth weight, lenght, head and thoracic circumferences, Apgar scores at 1 and 5 minutes, pediatric gestational age' and classification ${ }^{6}$ ).

The shock of birth was evaluated using the NACS ${ }^{4}$. This score is derivated from 20 items, each one with a sub-score of zero to 2 . The highest possible score is 40 . Subjects with a score of 35 or higher were considered vigorous newborns (VN). Subjects with a score below 35 where considered low vigor newborns (LVN). During the first contact with the newborn (prior to applying the NACS) the examiner determined the pediatric gestational age' and classified the newborns as small for gestational age (SGA), adequate for gestational age (AGA) or large for gestational age (LGA) ${ }^{6}$. All newborns were examinated by the same investigator, who was unaware of the maternal and obstetric data. The NACS was applied to the newborns at 4, 24 and 48 hours of life and, whenever possible, one hour before or after feeds.

The temperature in the exam room was kept between $22^{\circ} \mathrm{C}$ and $25^{\circ} \mathrm{C}$.

\section{RESULTS}

Maternal data: 311 mothers with ages ranging between 14 and 42 years (mean age $=25.5$ years) were studied. Most mothers were married (58.8\%), resided in Porto Alegre, RS (68.2\%), 
were Caucasian $(76.8 \%)$ and had had prenatal care $(92.3 \%)$. The average family income was equal 5.8 minimum wages (Brazil). The number of previous gestations ranged between 1 and 13 (mean = 2.4 ), the number of previous abortions ranged between 0 and 6 (mean $=0.25$ ), the number of previous vaginal deliveries ranged between zero and 12 (mean $=1.8)$ and the number of previous cesarean sections ranged between 1 and $8($ mean $=1.5)$. The obstetric gestational age ranged between 32 and 44 weeks (mean $=39.4$ ).

Obstetric data:. We evaluated 311 deliveries, $245(78.8 \%)$ by vaginal route. The duration of labor ranged between zero and 32 hours (mean $=6.7$ hours), with the second phase of labor between zero and 75 minutes (mean $=9.1$ minutes). The period of membrane rupture prior to delivery was between zero and 76 hours (mean $=3.6$ hours). The indications for the 66 deliveries by cesarean section were: 31 cephalo-pelvic disproportions (46.3\%), 20 mothers with previous cesarean sections (31.3\%), 14 pelvic presentations (20.9\%) and 1 twin gestation. Clear amniotic fluid was found in $75.6 \%$ of deliveries. Episiotomy was performed in $82 \%$ of vaginal deliveries. Labor was induced in $10.9 \%$ of the cases and instrumentation (forceps) was used in $9 \%$. Local anesthesia was applied in $83 \%$ of the vaginal deliveries. Some form of regional anesthesia was used in 69 deliveries (22.2\%): 28 deliveries had peridural block with bupivacaine, 2 with lidocaine and 5 with marcaine, 28 had subarachnoid block with bupivacaine, 4 with lidocaine and 2 with marcaine. A vasoconstricting agent was used in association with the anesthesic in $49.3 \%$ of the deliveries. Fentanyl was used on $45.5 \%$ of cesarean sections.

Newborn data: We studied 313 newborns. Most newborns were Caucasian (82.7\%), born by cephalic presentation (88.5\%) and male (52.7\%). A total of 234 newborns were classified as AGA, 66 were LGA and 13 were SGA. Birth weight ranged between $2060 \mathrm{~g}$ to $4780 \mathrm{~g}$ (mean $=3284.9 \mathrm{~g}$ ). Newborn lenght ranged between $40.5 \mathrm{~cm}$ and $54 \mathrm{~cm}($ mean $=49.1 \mathrm{~cm})$. Head and chest circumferences ranged between 30.0 and $38.5 \mathrm{~cm}$ (mean $=34.2 \mathrm{~cm}$ ) and $28.0 \mathrm{~cm}$ and $39.0 \mathrm{~cm}($ mean $=33.5 \mathrm{~cm})$, respectively. The Apgar score at 1 minute was between 1 and 10 (mean $=8.32$ ) and, at 5 minutes, between 7 and 10 (mean $=9.3$ ). The pediatric gestational age ranged between 37 and 44 weeks $($ mean $=39.5)$.

Shock of birth: We divided newborns into two groups according to their vigor on examination. The vigorous group (VG) was formed by 74 newborns (23.6\%) that kept a NACS score equal or greater than 35 at all times. The low vigor group (LVG) included 23 newborns $(7.3 \%$ ) that scored less than 35 points an all three examination time points. These two groups were then studied separately. Changes in newborn neurologic vigor were noted on different examinations, always with a trend towards improvement as the time progressed (Fig 1). There was a significant difference in the NACS

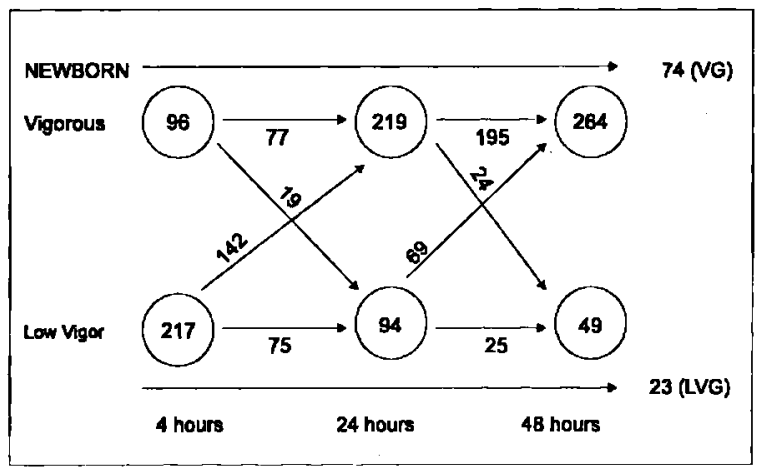




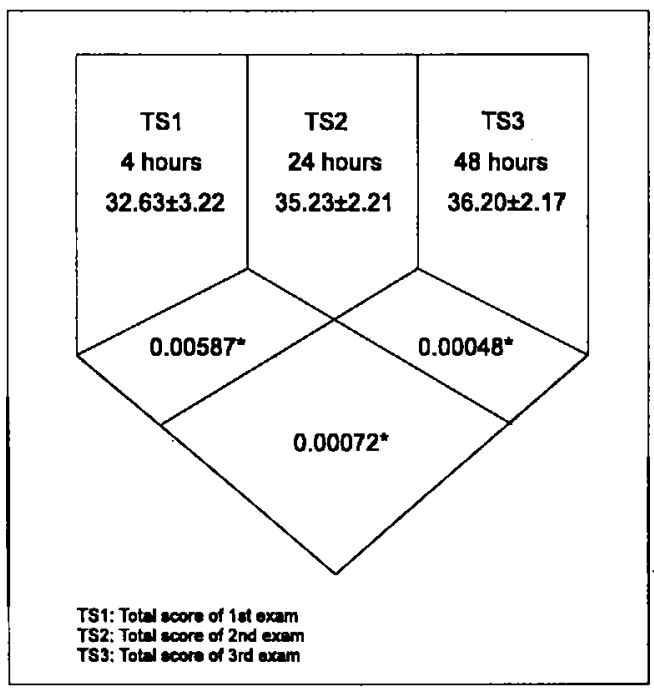

Fig 2. Comparison of the 3 NACS evaluations.

scores of the overall group when comparing baseline scores and the scores obtained at 4,24 and 48 hours (Fig 2).

Maternal data and the shock of birth: We used univariate and multivariate analysis to test the association of the shock of birth in the VG, LVG and overall group, in relation to 11 maternal variables. There was a statistically significant association between shock of birth and the following variables: obstetric gestational age, number of previous gestations, abortions and vaginal deliveries (Table 1).

Table J. Maternal data and shock of birth evaluated by NACS4.

\begin{tabular}{|c|c|c|c|c|}
\hline & \multicolumn{2}{|c|}{ univariate analysis } & \multicolumn{2}{|c|}{ multivariate analysis } \\
\hline & LVG $x$ VG & overall sample & LVG $x$ VG & overall sample \\
\hline age & NS & NS & NS & NS \\
\hline marital status & NS & NS & NS & NS \\
\hline residence & NS & NS & NS & NS \\
\hline race & NS & NS & NS & NS \\
\hline family income & NS & NS & NS & NS \\
\hline OGA & NS & 0.01 & NS & 0.01 \\
\hline prenatal care & NS & NS & NS & NS \\
\hline previous gestations & NS & 0.02 & NS & NS \\
\hline abortions & 0.03 & NS & 0.03 & NS \\
\hline vaginal delivery & NS & 0.01 & NS & 0.02 \\
\hline cesarean delivery & NS & NS & NS & NS \\
\hline
\end{tabular}


Table 2. Obstetric data and shock of birth evaluated by NACS.

\begin{tabular}{|c|c|c|c|c|}
\hline & \multicolumn{2}{|c|}{ univariate analysis } & \multicolumn{2}{|c|}{ multivariate analysis } \\
\hline & LVG $x$ VG & overall sample & LVG $\times$ VG & overall sample \\
\hline duration of labor & NS & NS & NS & NS \\
\hline duration of 2 nd stage & NS & NS & NS & NS \\
\hline duration of ROM & NS & NS & NS & NS \\
\hline placental weight & NS & NS & NS & NS \\
\hline mode of delivery & NS & NS & NS & NS \\
\hline aspect of amniotic fluid & NS & NS & 0.05 & 0.05 \\
\hline episiotomy & NS & NS & NS & NS \\
\hline induction & NS & NS & NS & NS \\
\hline instrumentation & NS & NS & NS & NS \\
\hline local anesthesia & NS & NS & NS & NS \\
\hline regional anesthesia & NS & NS & NS & NS \\
\hline vasoconstrictor agent & NS & NS & NS & NS \\
\hline fentanyl & NS & NS & NS & NS \\
\hline
\end{tabular}

LVG, low vigor group; VG, vigorous group; ROM, rupture of membranes; NS, not statistically significant ( $p>0.05$ ).

Table 3. Newborn datu and shock of birth evaluated by NACS4.

\begin{tabular}{|c|c|c|c|c|}
\hline & \multicolumn{2}{|c|}{ univariate analysis } & \multicolumn{2}{|c|}{ multivariate analysis } \\
\hline & LVG $\times$ VG & overall sample & LVG $\times$ VG & overall sample \\
\hline $\operatorname{sex}$ & NS & 0.01 & NS & 0.02 \\
\hline race & NS & NS & NS & NS \\
\hline presentation & NS & NS & NS & NS \\
\hline birth weight & NS & NS & 0.004 & NS \\
\hline lenght & NS & NS & NS & NS \\
\hline head circumference & NS & NS & NS & NS \\
\hline thoracic circumference & NS & NS & 0.001 & 0.003 \\
\hline Apgar (1 minute) & NS & NS & NS & NS \\
\hline Apgar (5 minutes) & NS & NS & NS & NS \\
\hline PGA & NS & NS & NS & NS \\
\hline classification* & NS & NS & NS & 0.007 \\
\hline
\end{tabular}

LVG, low vigor group; VG, vigorous group; PGA, pediatric gestutional age; NS, not statistically significant $(p>0.05)$.

*classification according Battaglia and Lubchenco ${ }^{6}$. 
Table 4. Multivariate analysis of overall data and shcok of birth evaluated by NACS'.

\begin{tabular}{lcc}
\hline & group evaluated & p value \\
\hline previous abortions & LVG x VG & 0.05 \\
aspect of amniotic fluid & LVG x VG & 0.05 \\
obstetric gestational age & overall sample & 0.05 \\
previous vaginal deliveries & overall sample & 0.006 \\
thoracic circumference (newborn) & overall sample & 0.003 \\
classification* (newborn) & overall sample & 0.03 \\
\hline
\end{tabular}

LVG, low vigor group; VG, vigorous group; *classification according to Battaglia and Lubchenco'.

Obstetric data and the shock of birth: The aspect of the amniotic fluid was the only obstetric variable associated with the shock of birth, as indicated by multivariate analysis. The presence of stained amniotic fluid at birth increased by 8.13 times the chance of a newborn being considered a low vigor newborn, when VG and LVG were compared (Table 2).

Newborn data and the shock of birth: We used univariate and multivariate analysis to test 11 associations between newborn data and the presence of shock of birth. Sex, birth weight, thoracic circumference and the Battaglia and Lubchenco ${ }^{6}$ classification were the newborn variables associated with the shock of birth (Table 3).

Overall multivariate analysis and the shock of birth: When all variables - maternal, obstetric and newborn - were considered in the equation of multivariate analysis, there was a significant association between shock of birth and obstetric gestational age, number of previous vaginal deliveries, number of previous abortions, aspect of the amniotic fluid, neonatal thoracic circumference and the Battaglia and Lubchenco ${ }^{6}$ classification (Table 4).

\section{DISCUSSION}

Scoring systems to evaluate newborn neurologic vigor have been available since the seventies. Even though several systems have been proposed, three gained more popularity: the Neonatal Behavioral Assessment Scale (NBAS - Brazelton, 1973) ${ }^{8}$, the Early Neonatal Neurobehavioral Scale (ENNS - Scanlon et al., 1974) ${ }^{32}$ and the Neurologic and Adaptative Capacity Score (NACS - Al nielTison et al., 1982) ${ }^{4}$, the later being considered a more comprehensive and practical neurobehavioral assessment system.

In our study, the NACS was applied to a 313 consecutive term newborns. This represents the largest sample which this system has been used in a clinical study.

Simion and colleages ${ }^{33}$ attempted to evaluate the relationship between mode of delivery and the neonatal neurological vigor, using the NBAS. The study indicated that the mode of delivery played no role in the neurobehavioral organization of the newborn. However, one must consider the fact the study sample had only 20 patients ( 10 born by vaginal delivery and 10 born by cesarean section). No attempts were made to establish the duration of the shock of birth in that study.

Previous publications seem to indicate that the neonatal neurological vigor is more dependent on lenght of labor than the mode of delivery. Neonatal neurologic vigor is thought to be lower in face of prolonged labor, where physical and emotional stresses could lead to elevation of endogenous catecholamines, changes in ventilatory physiology, acid-base balance and fetal well being $1,5,14,17,18,23,24,35$. The impression that the neonatal neurologic vigor would be lower after vaginal deliveries was 
described in the work of Fenton and Steer ${ }^{16}$ and Kuhnert et al. ${ }^{22}$. In our sample, the mode of delivery did not influence newborn vigor in a significant manner.

We demonstrated that the shock of birth lasted around 24 hours for most newborns. That is considerably less than the 72 hours originally proposed by Escardó and Coriat ${ }^{15}$ and the 48 hours suggested by Maekawa and Ochiai ${ }^{25}$.

Very few studies attempted to define the association between parity and neonatal neurologic vigor. According to Mingeot and Herbaut ${ }^{26}$, the neonatal neurologic vigor is not influenced by parity up to the fourth child. In our sample, parity influenced neonatal neurologic vigor at all. For example, previous abortions increased the chance of a newborn having low neurologic vigor by 2.45 times.

The role of the sex of the neonate in the neurobehavioral performance has been subject of investigation by several authors ${ }^{\mathbf{7 2 0 , 2 1 , 3 4}}$. It appears that male newborns have greater muscle vigor when compared to female newborns. Female newborns, on the other hand, are more receptive to certain stimuli, specially oral and cutaneous.Part of the differences seem to be related to hormones responsible for the in-utero differentiation ${ }^{20,21}$. In our study, the neurobehavioral differences between newboms of male and female sexes became significant only after few hours of observation. This may be related to the fact that the differences in behavior not be only intrinsically related to the sex of the newborn, but also may reflect the way that parents interact with newborns of different sexes ${ }^{21}$.

The neonatal neurologic evaluation scores are lower for the two extremes in birth weight, both for newborns weighing more than $4000 \mathrm{~g}$ and less than $2500 \mathrm{~g}$. There is evidence that SGA and LGA newborns exihibits worse neonatal neurologic performance ${ }^{2,29}$. In our sample, LGA newborns had a three fold chance of presenting with lower newborn vigor when compared to AGA newborns. SGA newborns also had lower vigor when compared to AGA newborns.

There was a significant correlation between thoracic circumference and the presence of the shock of birth, in our sample. The smaller the thoracic circumference, the greater were the chances of a newborn presenting with low vigor. Although we did not find any studies indicating such relationship, a small thoracic circumference might expose the cephalic pole to the effects of greater contractile forces during labor and delivery ${ }^{17}$.

We conclude that the mode of delivery, vaginal or cesarean section, does not influence the shock of birth in term newborns. We also establish that the duration of the shock of birth is shorter than previously described in the literature. Maternal, obstetrical and neonatal variables such as: gestational age, aspect of the amniotic fluid, parity, previous abortions, birth weight, sex and thoracic circumference of the newborn are associated with the development of the shock of birth.

\section{REFERENCES}

1. Abboud TK, Artal R, Henriksen EH, Earl S. Effects of spinal anesthesia on maternal circulating catecholamines. Am J Obst Gynecol 1982;142:252-254.

2. Abrol P, Kapoor R, Gathwala G, Tiwari S, Tiwari AD. Neonatal behavior in full-term small-for-date. Indian Pediatr 1994;31:785-789.

3. Amiel-Tison C. Neurologic disorders in neonates associated with abnormalities of pregnancy and birth. Curr Probl Pediatr 1973:3:3-37.

4. Amiel-Tison C, Barrier G, Shnider SM, Levinson G, Hughes SC, Stefuni SJ. A new neurologic and adaptative capacity score system for evaluating obstetric medicution in full-term newborns. Anesthesiology 1982;56:340-350.

5. Barton MD, Killam AP, Meschia G. Reponse of ovine uterine blood flow to epinephrine and norepinephrine. Proc Soc Exp Biol Med 1974;145:996-1003.

6. Battuglia FC, Lubchenco LO. A practical classification of newbom infants by weight and gestational age. Pediatrics 1967;71:159-163.

7. Brazelton TB. Effect of prenatal drugs on the behavior of the neonute. Am J Psychiatry 1970;126:1261-1266.

8. Brazelton TB. Neonutal behaviourul assessment scale. In Spastics Internutional Medical Publicutions. Clinics in development medicine. London: Heinemann, 1973.

9. Capurro H, Konichezky S, Fonseca D, Caldeyro-Barcia R. A simplified method for diagnosis of gestational age in the newborn infant. J Pediatr 1978;93:120-122.

10. Desmond MM, Franklin RR, Vallbona C, Hill RM, Plumb R, Arnold D, Watts J. The clinical behavior of the neonutal patient: the standard baby. Am J Dis Child 1961;102:732-733. 
11. Diament AJ. Contribuição para a sisternatização do exame neurológico de crianças normais no primeiro ano de vida. Tese de Doutorado, Faculdade de Medicina da Universidade de Sāo Paulo. Sāo Paulo, 1967.

12. Diament AJ. Introdução ù semiologia neurológica infuntil. In Diament AJ, Cypel S. Neurologia Infuntil-Lefevre. Ed 2. São Paulo: Atheneu, 1989: 1-4.

13. Diament AJ, Gherpelli JLD. Exame neurológico do recém-nascido. In Viaz FAC. Problemass neurológicos do recém-nascido. São Paulo: Sarvier, 1985:29-58.

14. Dixhoorn MJ, Visser GHA, Huisjes HJ, Fidler V, Touwen BCL. The relation between umbilical pH values and neonatal neurological morbity in full-term appropriate-for-date infants. Early Hum Dev 1985;11:32-42.

15. Escardó F, Coriat LF. Development of postural and tonic patterns in the newborn infant. Pediatr Clin North Am 1960;7:511-525.

16. Fenton A, Steer CM. Fetal distress. Am J Obst Gynecol 1962; 83:354-362.

17. Irested L, Langercrantz $H, H$ jemadhl $P$, Hägnevik $H$. Fetal and miternal plasma catecholamine levels at elective cesarean section under general or epidural anesthesia versus vaginal delivery. Am J Obst Gynecol 1982;142:1004-1010.

18. Jones CM, Greiss FC. The effect of labor on maternal and fetal circulating catecholamines. Am J Obst Gynecol 1982;144:149-153.

19. Koenigsberger MR. Judgement of fetal age: neurologic examination. Pedjatr Clin North Am 1966;13:823-833.

20. Koner AF. Individual differences at birth: implications for early experience and later development. Am J Orthopsychiat 1971;41:608-619.

21. Korner AF. Sex differences in newborns with special reference to differences in the organization of oril behavior. J Child Psychol Psychiat 1973;14:19-29.

22. Kuhnert BR, Harrison MJ, Linn PL, Kubnert PM. Effects of maternal epidural anesthesiu on neonatal behavior. Anesth Anslg 1984;63:301-308.

23. Low JA. Fetal acid-base status and outcome. In Hill A, Volpe JJ. Fetal neurology. New York: Raven Press, 1989:195-217.

24. Low JA, Pancham SR, Worthington D, Boston RW. Acid-buse, lactate, and pyruvate characteristics of the normal obstetric patient and fetus during the intrupartum period. Am J Obst Gynecol 1974;120:862-867.

25. Maekawa K, Ochiai Y. Electromyographic studies on flexor hypertonia of the extremities of newborn infants. Dev Med Child Neurol 1975; 17:440-446.

26. Mingeot R, Herbaut M. The functional status of the newborn infnat. Am J Obst Gynecol 1973;115:1138-1144.

27. Miura E. Assistência ao recém-nascido na sala de parto. In Miura E. Neonatologia: princípios e prática. Porto Alegre: Artes Médicas, 1991:53-56.

28. Nelson N. O início da respiração. In Avery GB. Neonatologia. Ed.2. Schvartsman S (tradutor). Rio de Janeiro: Medsi, 1984:148-170.

29. Otamiri G, Finnström O, Leijon I, Rydén G, Selbing A. Neurological condition of large-for-gestational age infants during the newborn period. Acta Paediatr Scand 1988;77:647-652.

30. Rotta NT. Problemas neurológicos do recém-nascido: o exame neurológico. In Miura E. Neonatologia: princípios e prática. Porto Alegre: Artes Médicas, 1991:305-307.

31. Scanlon JW. How is the baby? the Apgar score revisited. Clin Pediatr 1973;12:61-63.

32. Scanlon JW, Brown WV, Weiss JB, Alper MH. Neurobehavioural reponses of newbom infants after maternal epidural anesthesia. Anesthesiology 1974;40:121-128.

33. Simion F, Dondi M, Ferlini I, Valenzi E, Zanco F. Influence of the delivery on neonatal competence. Pediatr Med Chir 1992;14:29-32.

34. Touwen BCL, Huisjes HJ, Van-der-Zee ADJ, Eedengurg MECB, Smrkovsky M, Olinga AA. Obstetrical condition and neurological morbity: an analysis with the help of the optimality concept. Early Hum Dev 1980;4:207-228.

35. Zuspan FP, Cibils LA, Pose SV. Myometrical and curdiovascular reponses to alterations in plasma epinephrine and norepinephrine. Am J Obst Gynecol 1962;84:841-851. 